\title{
Impact of Resection Margin Distance on Survival of Pancreatic Cancer: A Systematic Review and Meta-Analysis
}

\author{
Kyung Su Kim, MD \\ Jeanny Kwon, MD² \\ Kyubo Kim, MD ${ }^{3}$

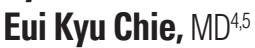

\begin{abstract}
Purpose
While curative resection is the only chance of cure in pancreatic cancer, controversies exist about the impact of surgical margin status on survival. Non-standardized pathologic report and different criteria on the R1 status made it difficult to implicate adjuvant therapy after resection based on the margin status. We evaluated the influence of resection margins on survival by meta-analysis.
\end{abstract}

\section{Materials and Methods}

We thoroughly searched electronic databases of PubMed, EMBASE, and Cochrane Library. We included studies reporting survival outcomes with different margin status: involved margin (RO mm), margin clearance with $\leq 1 \mathrm{~mm}(\mathrm{RO}-1 \mathrm{~mm})$, and margin with $>1 \mathrm{~mm}(\mathrm{R}>1 \mathrm{~mm})$. Hazard ratio (HR) for overall survival was extracted, and a random-effects model was used for pooled analysis.

\section{Results}

A total of eight retrospective studies involving 1,932 patients were included. Pooled HR for overall survival showed that patients with $\mathrm{R}>1 \mathrm{~mm}$ had reduced risk of death than those with R0-1 mm (HR, 0.74; 95\% confidence interval [Cl], 0.61 to 0.88; $p=0.001)$. In addition, patients with R0-1 mm had reduced risk of death than those with RO mm (HR, 0.81; 95\% $\mathrm{Cl}, 0.72$ to $0.91 ; \mathrm{p}<0.001)$. There was no heterogeneity between the included studies ( $I^{2}$ index, $42 \%$ and $0 \% ; p=0.10$ and $p=0.82$, respectively).

\section{Conclusion}

Our results suggest that stratification of the patients based on margin status is warranted in the clinical trials assessing the role of adjuvant treatment for pancreatic cancer.

\author{
Correspondence: Kyubo Kim, MD \\ Department of Radiation Oncology, \\ Ewha Womans University School of Medicine, \\ 1071 Anyangcheon-ro, Yangcheon-gu, \\ Seoul 07985, Korea \\ Tel: 82-2-2650-5334 \\ Fax: 82-2-2654-0363 \\ E-mail: kyubokim.ro@gmail.com \\ Received July 26, 2016 \\ Accepted August 15, 2016 \\ Published Online August 26, 2016
}

Key words

Meta-analysis, Pancreatic neoplasms, Resection margin, Systematic review

\section{Introduction}

Pancreatic ductal adenocarcinoma (PDAC) causes fourth leading cancer death in the United States in year 2014 [1]. Although only $10 \%$ to $20 \%$ has chance of resection, it is the only treatment that promises curing the disease [2]. Regarding the margin status after pancreaticoduodenectomy (PD) for PDAC, controversy exists about the impact of microscopic resection margin involvement (R1). Several studies have reported that it is an independent prognostic factor for poor long term survival [3-6], but not in other studies $[7,8]$. Main reason of this controversy partly originated from the issues of standardization of pathologic examination $[9,10]$. The standardization of pathological examination increased the rate of R1 resections after PD from 20\% to 50\% [11-13], and even to $>70 \%$ [14-17]. Moreover, there is ongoing debate concerning the definition of R1. According to the International Union Against Cancer (UICC) and the College of American Pathologists (CAP) reporting guidelines, R1 is 
defined as the microscopic presence of tumor cells at definite resection margin $[18,19]$. However, the Royal College of Pathologists (RCP) in the UK recommends that cases with microscopic evidence of tumor extension to within $1 \mathrm{~mm}$ from a circumferential margin or surface of the pancreatic resection specimen should be classified as R1 [20].

Accurate assessment of R1 is clinically important, not only because it provides prognostic information but stratification within the setting of randomized controlled trials of adjuvant therapy is based partly upon margin positivity. Appropriate identification of those patients who would most benefit is critical in the improvement of the management for PDAC.

Here, we conducted a systematic review and meta-analysis to assess the impact of resection margin distance on the survival of the patients with PDAC. We intended to identify survival outcomes with different margin status: involved margin $(\mathrm{R} 0 \mathrm{~mm})$, margin clearance with $\leq 1 \mathrm{~mm}(\mathrm{R} 0-1 \mathrm{~mm})$, and margin with $>1 \mathrm{~mm}(\mathrm{R}>1 \mathrm{~mm})$.

\section{Materials and Methods}

\section{Data sources and search strategy}

We performed a systematic literature review of published articles and unpublished abstracts, which reported overall survival of the patients with different surgical margin distance after resection of pancreatic cancer. Comprehensive searches were performed in the databases of PubMed, EMBASE, and Cochrane Library (last search update on 6 April 2015). The following key words with their corresponding $\mathrm{MeSH}$ terms were used: combined to maximize sensitivity: [(pancreatic cancer)[MESH] OR (pancrea* AND cancer) OR (pancrea* AND adenocarcinoma)][All Fields] AND [margin][TIAB]. Additionally, the references cited in retrieved articles were scrutinized by manual search.

\section{Study selection}

Two authors (K.S.K. and K.K.) independently reviewed search results. Inclusion criteria were observational studies that investigated survival outcomes according to different resection margin distance following PD for PDAC: involved margin $(\mathrm{R} 0 \mathrm{~mm})$, margin clearance with $\leq 1 \mathrm{~mm}(\mathrm{R} 0-1 \mathrm{~mm})$, and margin with $>1 \mathrm{~mm}(\mathrm{R}>1 \mathrm{~mm})$. To limit heterogeneity across the studies and to get more clinically meaningful results, we used following exclusion criteria: (1) studies that included pancreatic malignancy other than adenocarcinoma, (2) review articles or case reports, (3) studies that did not report surgical margin status, and (4) studies that did not provide sufficient data to acquire hazard ratio (HR) and its 95\% confidence interval (CI) of different margin status for overall survival (OS). Manual search for references of the eligible studies was performed to minimize potential missing data.

\section{Data extraction}

Data were extracted independently by two authors (K.S.K. and K.K.), and discrepancies were resolved by consensus. The following details were extracted: name of first author, institution, country, study period, publication year, number of participants, surgery type, $\mathrm{T}$ stage, $\mathrm{N}$ stage, adjuvant treatment details, follow-up period, and pathologic examination protocol.

\section{Risk of bias assessment}

Risk of bias was assessed by Risk of Bias Assessment tool for Non-randomized Studies (RoBANS), which was validated for assessing the risk of bias for nonrandomized studies [21]. It contains six domains: selection of participants, confounding variables, intervention measurement, blinding of outcome assessment, incomplete outcome data, and selective outcome reporting. Two authors (K.S.K. and K.K.) independently assessed and disagreements were resolved by consensus.

\section{Statistical analysis}

The OS outcome was measured in terms of the timeto-event HR of R0 mm compared with R0-1 mm and R0-1 $\mathrm{mm}$ with $\mathrm{R}>1 \mathrm{~mm}$. HR as well as its $95 \% \mathrm{CI}$ was directly extracted from the text or estimated using the published Kaplan-Meier curves using the methods of Tierney et al. [22]. Pooled HR was calculated using the random-effects model and presented with forest plots. Two-sided p-values less than 0.05 were considered statistically significant. A chi-square statistic was used to test for statistical heterogeneity, and $\mathrm{I}^{2}$ statistic was also calculated to evaluate the extent of variability attributable to statistical heterogeneity between trials. To assess the publication bias, we applied funnel plot method together with the Egger's regression test. All statistical analysis was done using RevMan 5.3 analysis software (Cochrane Collaboration, Copenhagen, Denmark). 


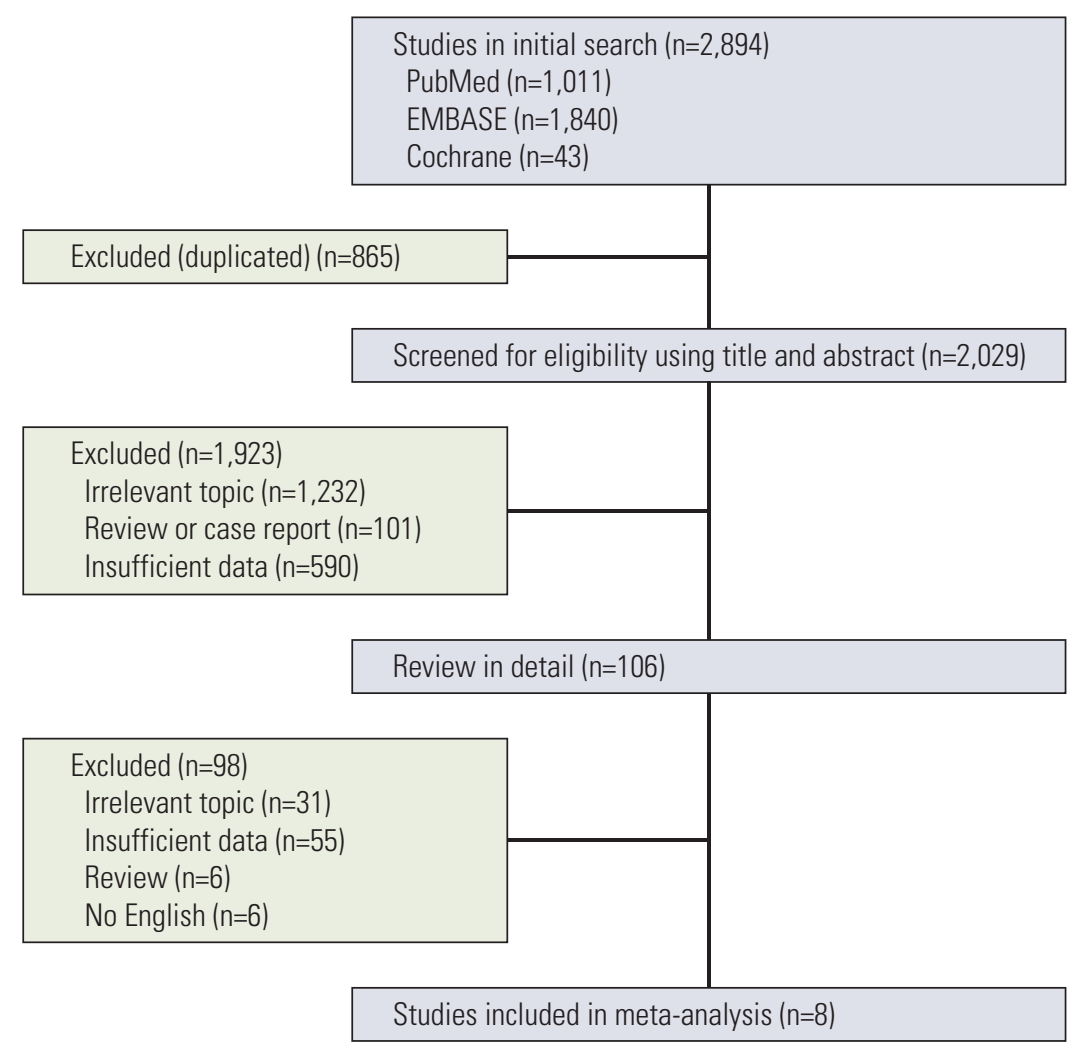

Fig. 1. Study selection process.

\section{Results}

\section{Selecting studies and characteristics of included studies}

Two thousand eight hundred ninety-four studies were obtained from the searches of electronic database using our searching strategy. A total of 106 articles were reviewed in detail. Eight studies were finally selected into this metaanalysis [16,17,23-28]. All of studies were retrospective observational cohort studies reporting survival outcome of resected pancreatic cancer at single center. Two studies were presented in abstract form only $[25,28]$. The details of study selection are shown in Fig. 1. Two studies were reported from Unites States, two studies from UK, two studies from Japan, one study from Germany, and one study from Australia. The patients with $\mathrm{R} 0 \mathrm{~mm}$ or $\mathrm{R} 0-1 \mathrm{~mm}$ constitute $27.4 \%$ to $78.5 \%$. Regarding surgical treatments, most of the patients underwent PD. In three studies, patients treated with distal pancreatectomy were included with the proportion of $19 \%$, $15.3 \%$, and $20.2 \%$, respectively $[23,26,27]$. Only two studies described the proportion of the $\mathrm{T}$ and $\mathrm{N}$ stage according to the resection margin status [26,27]. In four studies, the per- centage of the patients treated with adjuvant or neoadjuvant therapy was described. Basic characteristics of included studies are shown in Table 1. Details of pathologic evaluation of margin status are listed in Table 2. Details of pathologic examination protocol were described in six studies [14,20,29]. A summary of the risk of bias assessment is provided in Table 3.

\section{Impact of resection margin distance on survival}

We calculated overall pooled HR for OS with a random effects model. Chang et al. [23] reported disease-specific survival (DSS) instead of OS. Under the assumption that the DSS outcome might not differ from the OS, we pooled these data with the OS outcomes of the other seven studies. When we compared $\mathrm{R}>1 \mathrm{~mm}$ and $\mathrm{R} 0-1 \mathrm{~mm}, \mathrm{R}>1 \mathrm{~mm}$ had reduced risk of death than R0-1 mm (HR, 0.74; 95\% CI, 0.61 to 0.88 ; $\mathrm{p}=0.001$ ) (Fig. 2A). There was no heterogeneity between the included studies $\left(\mathrm{I}^{2}\right.$ index $\left.=42 \%, \mathrm{p}=0.10\right)$. When we compared $\mathrm{R} 0 \mathrm{~mm}$ with $\mathrm{R} 0-1 \mathrm{~mm}, \mathrm{R} 0-1 \mathrm{~mm}$ had reduced risk of death (HR, 0.81; 95\% CI, 0.72 to $0.91 ; \mathrm{p}<0.001$ ) (Fig. 2B). There was no heterogeneity among studies $\left(\mathrm{I}^{2}\right.$ index $\left.=0 \%, \mathrm{p}=0.82\right)$. 


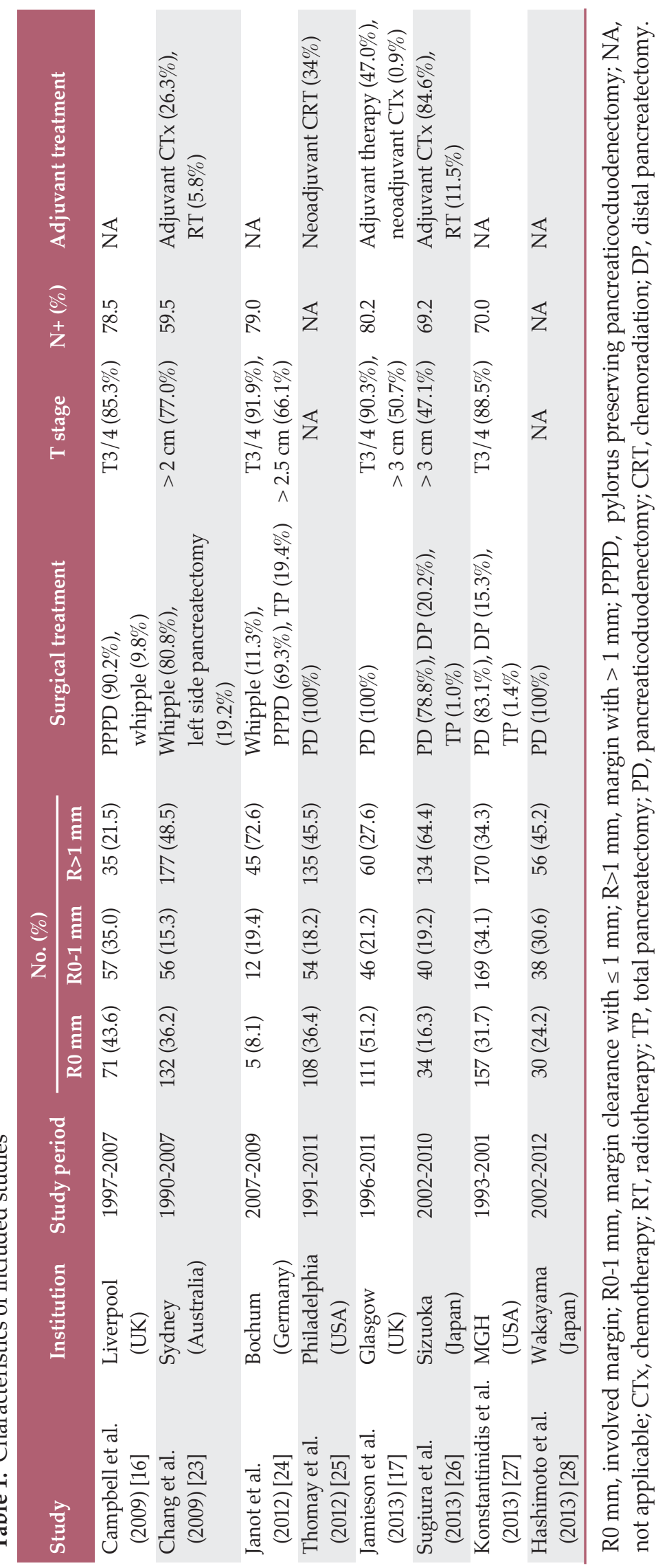


Table 2. Pathologic examination protocol

\begin{tabular}{|c|c|c|}
\hline Study & Protocol & Evaluated margin \\
\hline Campbell et al. (2009) [16] & $\mathrm{RCP}[20]$ & $\begin{array}{l}\text { Pancreatic transection margin } \\
\text { Medial (or superior mesenteric vessel) margin } \\
\text { Posterior margin } \\
\text { Proximal duodenal (or gastric) margin } \\
\text { Distal duodenal margin } \\
\text { Common bile duct margin }\end{array}$ \\
\hline Chang et al. (2009) [23] & Institutional & $\begin{array}{l}\text { Pancreatic neck margin } \\
\text { Portal vein/superior mesenteric vein margin } \\
\text { Superior mesenteric artery / retroperitoneal (uncinate) margin } \\
\text { Bile duct margin } \\
\text { Proximal gastric/duodenal margin } \\
\text { Distal duodenal margin }\end{array}$ \\
\hline Janot et al. (2012) [24] & Modified LEEPP [14] & $\begin{array}{l}\text { Anterior margin } \\
\text { Posterior margin (uncinate process) } \\
\text { Superior mesenteric vein groove circumferential resection margin } \\
\text { Transection margin } \\
\text { (pancreatic neck, bile duct, and duodenum margin) }\end{array}$ \\
\hline Thomay et al. (2012) [25] & NA & NA \\
\hline Jamieson et al. (2013) [17] & $\operatorname{RCP}[20,31]$ & $\begin{array}{l}\text { Posterior margin } \\
\text { Anterior margin } \\
\text { Medial margin } \\
\text { Pancreatic transection margin }\end{array}$ \\
\hline Sugiura et al. (2013) [26] & Japan Pancreas Society [30] & $\begin{array}{l}\text { Pancreatic transection margin } \\
\text { Superior mesenteric artery margin } \\
\text { Posterior margin } \\
\text { Proximal bile duct margin }\end{array}$ \\
\hline Konstantinidis et al. (2013) [27] & Staley et al. [29] & $\begin{array}{l}\text { Common bile duct margin } \\
\text { Pancreatic transection (neck) margin } \\
\text { Posterior/retroperitoneal margin } \\
\text { Uncinate (superior mesenteric artery) margin }\end{array}$ \\
\hline Hashimoto et al. (2013) [28] & NA & NA \\
\hline
\end{tabular}

RCP, Royal College of Pathologist; LEEPP, Leeds Pathology Protocol; NA, not applicable.

\section{Publication bias}

A funnel plot of the effect size for each subgroup category of the trial against the precision showed no asymmetry (Fig. 3). Egger's regression test for potential publication bias yielded no potential unpublished studies. (Egger's test, $\mathrm{p}=0.373$ for between $\mathrm{R}>1 \mathrm{~mm}$ and $\mathrm{R} 0-1 \mathrm{~mm}, \mathrm{p}=0.852$ for between $\mathrm{R} 0-1 \mathrm{~mm}$ and $\mathrm{R} 0 \mathrm{~mm}$, respectively).

\section{Discussion}

The reported R1 rates after PD for PDAC showed a high variation ranging from $17 \%$ to $85 \%$. Previous studies which reported low R1 resection rates of less than $20 \%$ had local recurrence rate of $60 \%-80 \%$ [7,30,31]. These findings indicated a considerable underestimation of the true R1 status. Lack of a standardized pathological examination protocol and different definitions of resection margin are probably the main reasons for the high variation in reported R1 rates. In this meta-analysis, six studies explained details of standardized pathological examination. Eventually, when ' $1 \mathrm{~mm}$ rule' was applied, R1 rates were greater than $35.6 \%$ except a study by Janot et al. [24] which had low number of patients.

Controversy exists over the anterior surface of PD specimens as to whether it should be regarded as part of the resection margin. Anterior surface as a resection margin was recommended in Japan [32,33] and in Europe [14]. Because the surgeon does not transect any tissues in this area, however, anterior surface was not regarded a true resection mar- 
Table 3. A summary of risk of bias assessment using the Risk of Bias Assessment Tool for Non-randomized Studies (RoBANS)

\begin{tabular}{|c|c|c|c|c|c|c|}
\hline \multirow[b]{2}{*}{ Study } & \multicolumn{2}{|c|}{ Selection } & \multirow{2}{*}{$\begin{array}{c}\text { Performance } \\
\begin{array}{c}\text { Measurement } \\
\text { of exposure }\end{array}\end{array}$} & \multirow{2}{*}{$\begin{array}{c}\text { Detection } \\
\text { Blinding } \\
\text { of outcome } \\
\text { assessments }\end{array}$} & \multirow{2}{*}{$\begin{array}{c}\text { Attrition } \\
\text { Incomplete } \\
\text { outcome } \\
\text { data }\end{array}$} & \multirow{2}{*}{$\begin{array}{c}\text { Reporting } \\
\text { Selective } \\
\text { outcome } \\
\text { reporting }\end{array}$} \\
\hline & $\begin{array}{l}\text { Selection of } \\
\text { participants }\end{array}$ & $\begin{array}{l}\text { Confounding } \\
\text { variables }\end{array}$ & & & & \\
\hline Campbell et al. (2009) [16] & Low & Low & Low & Low & Unclear & Low \\
\hline Chang et al. (2009) [23] & Low & Low & Low & Low & Low & Low \\
\hline Janot et al. (2012) [24] & Low & Low & Low & Low & Unclear & Low \\
\hline Thomay et al. (2012) [25] & Low & High & Low & Low & Unclear & Unclear \\
\hline Jamieson et al. (2013) [17] & Low & Low & Low & Low & Low & Low \\
\hline Sugiura et al. (2013) [26] & Low & Low & Low & Low & Unclear & Low \\
\hline Konstantinidis et al. (2013) [27] & Low & High & Low & Low & Unclear & Low \\
\hline Hashimoto et al. (2013) [28] & Low & High & Low & Low & Unclear & Unclear \\
\hline
\end{tabular}

gin. Some authors proposed that assessment of this margin should be excluded from a standardized pathological examination protocol [15], or that the " $0 \mathrm{~mm}$ " clearance rule should be used $[9,34]$. While most common involved margin in the pancreatic cancer is the medial or posterior resection margin [15], Jamieson et al. [35] reported that R1 at anterior surface made up $12.8 \%$ of the R1 cases and that these patients presented favorable outcome than those with R1 at medial or transection margin. In this meta-analysis, anterior surface was considered a resection margin in only two studies $[17,24]$.

The ' $1 \mathrm{~mm}$ rule' has been adopted from the association between the circumferential margin status and local recurrence of the rectal cancer. Verbeke et al. [36] reported that tumor growth in pancreatic head cancers is more dispersed than in rectal cancer, claiming that $1 \mathrm{~mm}$ definition needs to be considered. Single institutional studies including encompassed ones in this meta-analysis reported the association of the margin clearance with OS. Chang et al. [23] and Jamieson et al. [17] demonstrated that margin clearance by at least $1.5 \mathrm{~mm}$ identified a subgroup of patients which may potentially achieve long-term survival. Gebauer et al. [37] reported that margin clearance of $2 \mathrm{~mm}$ or greater as an independent prognostic factor for OS. However, because each study had limited number of patients, any conclusive result could not be drawn. Through the pooled HR of current meta-analysis including 1,932 patients, we could verify that $\mathrm{R}>1 \mathrm{~mm}$ had reduced risk of death than R0-1 mm, and R0-1 mm also had reduced risk of death than $\mathrm{R} 0 \mathrm{~mm}$.

While adjuvant chemotherapy is currently the standard treatment for patients following a potentially curative PD for PDAC in Europe, chemoradiotherapy as an adjuvant treatment is considered based on the margin status. Two recent meta-analyses have suggested that patients with R1 status appear to benefit from postoperative chemoradiotherapy [8,38]. Chang et al. [23] noted that patients with close resection margins $(<1.5 \mathrm{~mm})$ may have a better response to adjuvant radiotherapy compared with involved margins (R0 $\mathrm{mm}$ ) as a result of the probable low volume of residual local disease, and potentially constitute a subgroup that is most likely to have the greatest benefit. In conjunction with these results, our results could be used in identifying a subgroup that will benefit from radiotherapy after PD for PDAC.

Several studies examined the effect of neoadjuvant treatment on resection margin status [7,39-42]. Katz et al. [40] reported that patients who received chemoradiation had longer superior mesenteric artery margin distances than those who did not. In the study by Delpero et al. [42], neoadjuvant treatment was correlated with a reduced risk for a positive posterior margin. In contrary, Raut et al. [7] reported that neoadjuvant therapy was not a statistically significant predictor of margin status. In one study by Thomay et al. [25] included in this meta-analysis, neoadjuvant treatment was given to $34 \%$ of the patients. The patients with $\mathrm{R} 0-1 \mathrm{~mm}$ had similar risk of death compared to $\mathrm{R}>1 \mathrm{~mm}$, and $34 \%$ reduction of death compared to R0 $\mathrm{mm}$ in that study. One might argue that high proportion of neoadjuvant treatment than other studies might explain the result. However, the hypothesis that neoadjuvant treatment could decrease the adverse effect of R1 is not evidenced by randomized trials. Further studies to investigate the role of neoadjuvant treatment using a standardized pathological examination protocol are warranted.

Major limitation of our study is that included studies did not provide adequate information on the distribution of prognostic factors according to margin status. Given that most of the patients were of T3-4 and/or lymph node involvement, stratification according to resection margin sta- 


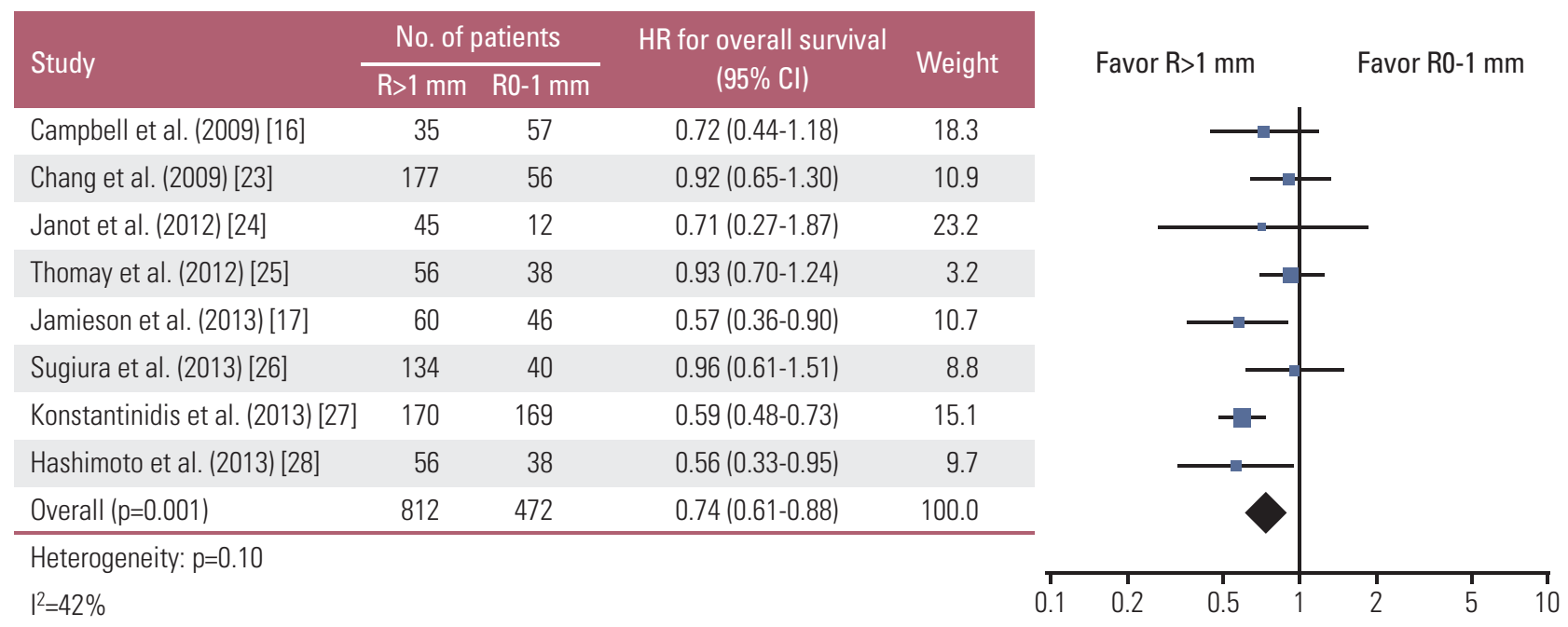

\begin{tabular}{|c|c|c|c|c|c|c|c|}
\hline \multirow{2}{*}{ Study } & \multicolumn{2}{|c|}{ No. of patients } & \multirow{2}{*}{$\begin{array}{l}\text { HR for overall survival } \\
\qquad(95 \% \mathrm{CI})\end{array}$} & \multirow{2}{*}{ Weight } & \multirow{2}{*}{\multicolumn{2}{|c|}{ Favor R0-1 mm }} & \multirow{2}{*}{ Favor $\mathrm{RO} \mathrm{mm}$} \\
\hline & $\mathrm{Ro}-1 \mathrm{~mm}$ & $\mathrm{RO} \mathrm{mm}$ & & & & & \\
\hline Campbell et al. (2009) [16] & 57 & 71 & $0.83(0.56-1.23)$ & 8.6 & & & \\
\hline Chang et al. (2009) [23] & 56 & 132 & $0.82(0.59-1.14)$ & 12.3 & & & \\
\hline Janot et al. (2012) [24] & 12 & 5 & $0.48(0.14-1.65)$ & 0.9 & & & \\
\hline Thomay et al. (2012) [25] & 38 & 108 & $0.66(0.49-0.89)$ & 15.0 & & & \\
\hline Jamieson et al. (2013) [17] & 46 & 111 & $0.98(0.68-1.41)$ & 9.9 & & & \\
\hline Sugiura et al. (2013) [26] & 40 & 34 & $0.87(0.50-1.51)$ & 4.3 & & & \\
\hline Konstantinidis et al. (2013) [27] & 169 & 157 & $0.82(0.69-0.97)$ & 44.6 & & & \\
\hline Hashimoto et al. (2013) [28] & 38 & 30 & $0.83(0.48-1.44)$ & 4.4 & & & \\
\hline Overall $(p<0.001)$ & 472 & 648 & $0.81(0.72-0.91)$ & 100.0 & & & \\
\hline \multicolumn{8}{|l|}{ Heterogeneity: $p=0.82$} \\
\hline$P^{2}=0 \%$ & & & & & 0.1 & 0.2 & 5 \\
\hline
\end{tabular}

Fig. 2. Forest plot for $H R$ of the $R>1 \mathrm{~mm}$ and $\mathrm{R} 0-1 \mathrm{~mm}$ margin (A) or R0-1 mm and $\mathrm{R} 0 \mathrm{~mm}$ margin (B). R0 mm, involved margin; R0-1 mm, margin clearance with $\leq 1 \mathrm{~mm}$; $\mathrm{R}>1 \mathrm{~mm}$, margin with $>1 \mathrm{~mm}$; HR, hazard ratio; $\mathrm{CI}$, confidence interval.

tus could not be assessed except two studies [26,27]. Moreover, except a study by Sugiura et al. [26] detailed proportion of the patients who received adjuvant or neoadjuvant therapy among the different resection margin could not be evaluated. In addition, two studies in this meta-analysis were reported in abstract form only $[25,28]$. However, excluding these two studies did not alter the pooled result (for $\mathrm{R}>1 \mathrm{~mm}$ and R0-1 mm: HR, 0.73 ; 95\% CI, 0.58 to $0.92 ; \mathrm{p}=0.007$; for
R0-1 mm and R0 mm: HR, 0.78; 95\% CI, 0.65 to $0.94 ; \mathrm{p}=0.010$ ). Lastly, in three studies, the patients with distal pancreatectomy were included with the proportion of $15.3 \%-20.2 \%$ $[23,26,27]$. However, effect size was not significantly different by excluding these three studies (for $\mathrm{R}>1 \mathrm{~mm}$ and $\mathrm{R} 0-1 \mathrm{~mm}$ : HR, $0.71 ; 95 \%$ CI, 0.58 to $0.88 ; \mathrm{p}=0.001$; for $\mathrm{R} 0-1 \mathrm{~mm}$ and R0 mm: HR, $0.84 ; 95 \%$ CI, 0.74 to $0.95 ; p=0.007$ ). 
A

B
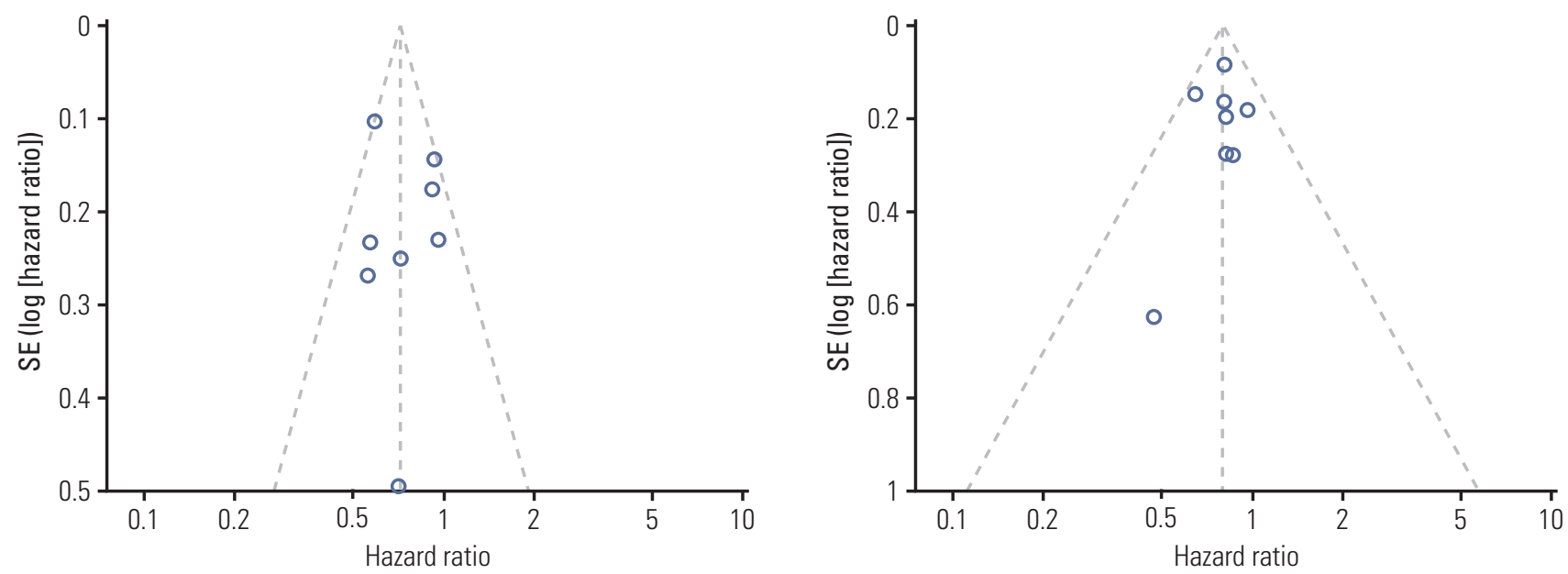

Fig. 3. Funnel plot of the included studies regarding $\mathrm{R}>1 \mathrm{~mm}$ and $\mathrm{R} 0-1 \mathrm{~mm}$ margin (A) or R0-1 mm and R0 mm margin (B).

\section{Conclusion}

While existing controversy about R1 status in the resected pancreatic cancer, our meta-analysis suggests that patients with resection margin with $0-1 \mathrm{~mm}$ had reduced risk of death than those with involved margin status, and greater risk of death than those with $>1 \mathrm{~mm}$ margin. Based on these result, stratification of patients based on margin distance with standardized pathological examination should be implicated in the future clinical trial of adjuvant therapy for pancreatic cancer.

\section{Conflicts of Interest}

Conflict of interest relevant to this article was not reported.

\section{References}

1. Siegel R, Ma J, Zou Z, Jemal A. Cancer statistics, 2014. CA Cancer J Clin. 2014;64:9-29.

2. Bilimoria KY, Bentrem DJ, Ko CY, Stewart AK, Winchester DP, Talamonti MS. National failure to operate on early stage pancreatic cancer. Ann Surg. 2007;246:173-80.

3. Neoptolemos JP, Stocken DD, Dunn JA, Almond J, Beger HG, Pederzoli $\mathrm{P}$, et al. Influence of resection margins on survival for patients with pancreatic cancer treated by adjuvant chemoradiation and/or chemotherapy in the ESPAC-1 randomized controlled trial. Ann Surg. 2001;234:758-68.

4. Menon KV, Gomez D, Smith AM, Anthoney A, Verbeke CS. Impact of margin status on survival following pancreatoduo- denectomy for cancer: the Leeds Pathology Protocol (LEEPP). HPB (Oxford). 2009;11:18-24.

5. Hartwig W, Hackert T, Hinz U, Gluth A, Bergmann F, Strobel $\mathrm{O}$, et al. Pancreatic cancer surgery in the new millennium: better prediction of outcome. Ann Surg. 2011;254:311-9.

6. Gnerlich JL, Luka SR, Deshpande AD, Dubray BJ, Weir JS, Carpenter $\mathrm{DH}$, et al. Microscopic margins and patterns of treatment failure in resected pancreatic adenocarcinoma. Arch Surg. 2012;147:753-60.

7. Raut CP, Tseng JF, Sun CC, Wang H, Wolff RA, Crane CH, et al. Impact of resection status on pattern of failure and survival after pancreaticoduodenectomy for pancreatic adenocarci- 
noma. Ann Surg. 2007;246:52-60.

8. Butturini G, Stocken DD, Wente MN, Jeekel H, Klinkenbijl JH, Bakkevold $\mathrm{KE}$, et al. Influence of resection margins and treatment on survival in patients with pancreatic cancer: metaanalysis of randomized controlled trials. Arch Surg. 2008;143: 75-83.

9. Verbeke CS, Menon KV. Redefining resection margin status in pancreatic cancer. HPB (Oxford). 2009;11:282-9.

10. Schlitter AM, Esposito I. Definition of microscopic tumor clearance (r0) in pancreatic cancer resections. Cancers (Basel). 2010;2:2001-10.

11. Wagner M, Redaelli C, Lietz M, Seiler CA, Friess H, Buchler MW. Curative resection is the single most important factor determining outcome in patients with pancreatic adenocarcinoma. Br J Surg. 2004;91:586-94.

12. Kuhlmann K, de Castro S, van Heek T, Busch O, van Gulik T, Obertop $\mathrm{H}$, et al. Microscopically incomplete resection offers acceptable palliation in pancreatic cancer. Surgery. 2006;139: 188-96.

13. Westgaard A, Tafjord S, Farstad IN, Cvancarova M, Eide TJ, Mathisen $\mathrm{O}$, et al. Resectable adenocarcinomas in the pancreatic head: the retroperitoneal resection margin is an independent prognostic factor. BMC Cancer. 2008;8:5.

14. Verbeke CS, Leitch D, Menon KV, McMahon MJ, Guillou PJ, Anthoney A. Redefining the R1 resection in pancreatic cancer. Br J Surg. 2006;93:1232-7.

15. Esposito I, Kleeff J, Bergmann F, Reiser C, Herpel E, Friess H, et al. Most pancreatic cancer resections are R1 resections. Ann Surg Oncol. 2008;15:1651-60.

16. Campbell F, Smith RA, Whelan P, Sutton R, Raraty M, Neoptolemos JP, et al. Classification of $\mathrm{R} 1$ resections for pancreatic cancer: the prognostic relevance of tumour involvement within $1 \mathrm{~mm}$ of a resection margin. Histopathology. 2009;55: 277-83.

17. Jamieson NB, Chan NI, Foulis AK, Dickson EJ, McKay CJ, Carter CR. The prognostic influence of resection margin clearance following pancreaticoduodenectomy for pancreatic ductal adenocarcinoma. J Gastrointest Surg. 2013;17:511-21.

18. Sobin LH, Gospodarowicz MK, Wittekind C. International Union Against Cancer. TNM classification of malignant tumours. 7th ed. Oxford: Wiley-Blackwell; 2009.

19. College of American Pathologists. Protocol for the examination of specimens from patients with carcinoma of the exocrine pancreas [Internet]. Northfield, IL: College of American Pathologists [cited 2015 Jun 1]. Available from: http://www. cap.org/web/ home/ resources / cancer-reporting-tools / cancer-protocol-templates.

20. The Royal College of Pathologists. Standards and minimum datasets for reporting cancers: dataset for the histopathological reporting of carcinomas of the pancreas, ampulla of Vater and common bile duct. London: The Royal College of Pathologists; 2010.

21. Kim SY, Park JE, Lee YJ, Seo HJ, Sheen SS, Hahn S, et al. Testing a tool for assessing the risk of bias for nonrandomized studies showed moderate reliability and promising validity. J Clin Epidemiol. 2013;66:408-14.
22. Tierney JF, Stewart LA, Ghersi D, Burdett S, Sydes MR. Practical methods for incorporating summary time-to-event data into meta-analysis. Trials. 2007;8:16.

23. Chang DK, Johns AL, Merrett ND, Gill AJ, Colvin EK, Scarlett $\mathrm{CJ}$, et al. Margin clearance and outcome in resected pancreatic cancer. J Clin Oncol. 2009;27:2855-62.

24. Janot MS, Kersting S, Belyaev O, Matuschek A, Chromik AM, Suelberg D, et al. Can the new RCP R0/R1 classification predict the clinical outcome in ductal adenocarcinoma of the pancreatic head? Langenbecks Arch Surg. 2012;397:917-25.

25. Thomay AA, Hoffman JP, Chun YS. Defining resection margins in pancreatic cancer after neoadjuvant chemoradiotherapy. Gastroenterology. 2012;142(Suppl 1):S1062-3.

26. Sugiura T, Uesaka K, Mihara K, Sasaki K, Kanemoto H, Mizuno T, et al. Margin status, recurrence pattern, and prognosis after resection of pancreatic cancer. Surgery. 2013;154: 1078-86.

27. Konstantinidis IT, Warshaw AL, Allen JN, Blaszkowsky LS, Castillo CF, Deshpande V, et al. Pancreatic ductal adenocarcinoma: is there a survival difference for R1 resections versus locally advanced unresectable tumors? What is a "true" R0 resection? Ann Surg. 2013;257:731-6.

28. Hashimoto Y, Murakami Y, Uemura K, Sudo T, Kondo N, Sueda T. Impact of margin clearance on survival after pancreaticoduodenectomy for pancreatic ductal adenocarcinoma: what is a "true" negative margin? Gastroenterology. 2013; 144(Suppl 1):S1128.

29. Staley CA, Cleary KR, Abbruzzese JL, Lee JE, Ames FC, Fenoglio CJ, et al. The need for standardized pathologic staging of pancreaticoduodenectomy specimens. Pancreas. 1996; 12:373-80.

30. Van den Broeck A, Sergeant G, Ectors N, Van Steenbergen W, Aerts R, Topal B. Patterns of recurrence after curative resection of pancreatic ductal adenocarcinoma. Eur J Surg Oncol. 2009;35:600-4.

31. Kayahara M, Nagakawa T, Ueno K, Ohta T, Takeda T, Miyazaki I. An evaluation of radical resection for pancreatic cancer based on the mode of recurrence as determined by autopsy and diagnostic imaging. Cancer. 1993;72:2118-23.

32. Nagakawa T, Nagamori M, Futakami F, Tsukioka Y, Kayahara M, Ohta T, et al. Results of extensive surgery for pancreatic carcinoma. Cancer. 1996;77:640-5.

33. Japan Pancreas Society. General rules for the study of pancreatic cancer. 2nd ed. Tokyo: Kanehara; 2003.

34. Verbeke CS. Resection margins and R1 rates in pancreatic cancer: are we there yet? Histopathology. 2008;52:787-96.

35. Jamieson NB, Foulis AK, Oien KA, Going JJ, Glen P, Dickson EJ, et al. Positive mobilization margins alone do not influence survival following pancreatico-duodenectomy for pancreatic ductal adenocarcinoma. Ann Surg. 2010;251:1003-10.

36. Verbeke CS, Knapp J, Gladhaug IP. Tumour growth is more dispersed in pancreatic head cancers than in rectal cancer: implications for resection margin assessment. Histopathology. 2011;59:1111-21.

37. Gebauer F, Tachezy M, Vashist YK, Marx AH, Yekebas E, Izbicki JR, et al. Resection margin clearance in pancreatic can- 
cer after implementation of the Leeds Pathology Protocol (LEEPP): clinically relevant or just academic? World J Surg. 2015;39:493-9.

38. Stocken DD, Buchler MW, Dervenis C, Bassi C, Jeekel H, Klinkenbijl JH, et al. Meta-analysis of randomised adjuvant therapy trials for pancreatic cancer. Br J Cancer. 2005;92:137281.

39. Pingpank JF, Hoffman JP, Ross EA, Cooper HS, Meropol NJ, Freedman G, et al. Effect of preoperative chemoradiotherapy on surgical margin status of resected adenocarcinoma of the head of the pancreas. J Gastrointest Surg. 2001;5:121-30.

40. Katz MH, Wang $\mathrm{H}$, Balachandran A, Bhosale $\mathrm{P}$, Crane $\mathrm{CH}$,
Wang X, et al. Effect of neoadjuvant chemoradiation and surgical technique on recurrence of localized pancreatic cancer. J Gastrointest Surg. 2012;16:68-78.

41. Barbier L, Turrini O, Gregoire E, Viret F, Le Treut YP, Delpero JR. Pancreatic head resectable adenocarcinoma: preoperative chemoradiation improves local control but does not affect survival. HPB (Oxford). 2011;13:64-9.

42. Delpero JR, Bachellier P, Regenet N, Le Treut YP, Paye F, Carrere $\mathrm{N}$, et al. Pancreaticoduodenectomy for pancreatic ductal adenocarcinoma: a French multicentre prospective evaluation of resection margins in 150 evaluable specimens. HPB (Oxford). 2014;16:20-33. 